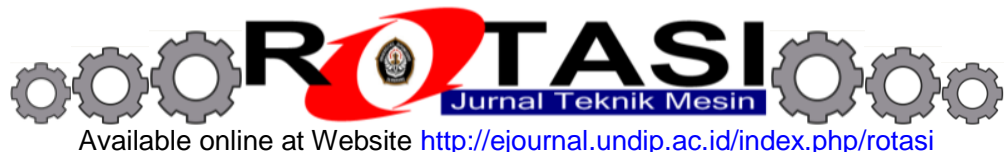

Available online at Website http://ejournal.undip.ac.id/index.php/rotasi

\title{
PENGARUH WAKTU DAN TEMPERATUR SINTER TERHADAP DENSITAS DAN POROSITAS KOMPOSIT ALUMINIUM YANG DIPERKUAT LIMBAH GEOTHERMAL
}

\author{
*Sulardjaka, M.S. Rahman, C. Wahyudianto \\ Jurusan Teknik Mesin, Fakultas Teknik, Universitas Diponegoro \\ Jl. Prof. Sudharto, SH., Tembalang-Semarang 50275, Telp. +62247460059 \\ *E-mail: sulardjaka@undip.ac.id
}

\begin{abstract}
ABSTRAK
Pembuangan limbah geothermal ke lingkungan akan mengakibatkan masalah pencemaran lingkungan. Untuk mengatasi masalah pembuangan limbah geothermal ke lingkungan, perlu dilakukan upaya untuk memanfaakan limbah geothermal tersebut. Pada penelitian ini memanfaatkan limbah geothermal sebagai penguat pada bahan komposit matrik aluminium. Proses pembuatan komposit dilakukan dengan metode metalurgi serbuk. Pembuatan green body komposit dilakukan dengan penekanan secara uniaxial dengan tekanan kompaksi $250 \mathrm{MPa}$. Sintering dilakukan di dalam dapur elektrik pada lingkungan gas argon dengan variasi temperatur sinter $550{ }^{\circ} \mathrm{C}, 550{ }^{\circ} \mathrm{C}$ dan $600{ }^{\circ} \mathrm{C}$ dengan waktu penahanan sinter 1,2 dan 4 jam. Pengujian terhadap densitas dilakukan berdasarkan hukum Archimedes. Porositas bahan komposit dihitung dengan membandingkan densitas hasil pengukuran dengan densitas teoritis.
\end{abstract}

Kata kunci: komposit, limbah geothermal, temperatur sinter, waktu sinter

\section{PENDAHULUAN}

Sebagai negara yang memiliki banyak gunung berapi, Indonesia memiliki sumber panas bumi berlimpah. Kebijakan Energi Nasional (KEN) yang tertuang dalam Perpres No. 5 tahun 2006 menyebutkan bahwa, pada tahun 2025 konstribusi energi panas bumi diharapkan mencapai $5 \%$ atau sekitar 9500 MW. Penggunaan energi panas bumi sebagai Pembangkit Listrik Tenaga Panas Bumi (PLTPB) memberikan dampak positif pada pembangunan nasional, karena panas bumi merupakan energi terbarukan yang ketersediaannya melimpah.

Penggunaan energi panas bumi memiliki nilai positif karena dapat menekan penggunaan energi fosil. Namun penggunaan panas bumi sebagai sumber energi juga memiliki dampak negatif yang harus dicari jalan keluarnya. Salah satu dampak negatif penggunaan energi panas bumi adalah produksi energi panas bumi menghasilkan limbah. Limbah yang dihasilkan berupa geothermal brine dan sludge [1]. Limbah padat (sludge) berasal dari endapan pada proses pengolahan limbah cair (geothermal brine) dan kerak silika dari pipa-pipa instalasi Pembangkit Listrik Tenaga Panas Bumi (PLTPB). Jumlah limbah geothermal yang dihasilkan sebuah PLTPB cukup besar. Sebagai ilustrasi pada pembangkit listrik berdaya $620 \mathrm{MW}$, limbah padat yang dihasilkan mencapai 11.000 ton perjam [2]. Salah satu PLTPB yang ada di Indonesia adalah Pada PLTPB Geo Dipa di Dieng Jawa Tengah. Dalam operasinya, PLTPB Geo Dipa menghasilkan limbah geothermal sebesar 165 Ton per bulan. Limbah lumpur geothermal tersebut selama ini hanya dibuang ke tempat penampungan limbah [3].

Limbah geothermal dari PLTPB Geo Dieng selama ini belum dimanfaatkan dan hanya dibuang di tempat penimbunan. Karakterisasi terhadap limbah geothermal menunjukkan bahwa limbah geothermal mengandung garam logam dan logam berat (besi, titanium, mangan, seng, arsen, boron, cadmium, timbal, nikel, tembaga) yang berpotensi mencemari lingkungan. Sampai saat ini, penelitian tentang pemanfaatan limbah geothermal lebih banyak difokuskan untuk membuat silika dari limbah geothermal [4]. Limbah geothermal memiliki kandungan silika yang cukup tinggi [5]. Kandungan silika pada limbah geothermal membuat limbah geothermal berpotensi untuk dimanfaatkan sebagai penguat bahan komposit matrik aluminium. Hasil penelitian Zuhailawati, dkk. [6] yang menyebutkan bahwa penambahan silika $\left(\mathrm{SiO}_{2}\right)$ hingga $30 \%$ meningkatkan kekerasan dan modulus of rupture komposit matrik aluminium. Hasil dari penelitian ini sama dengan hasil penelitian Hamouda, dkk. [7] yang menyebutkan bahwa penambahan bahan $\mathrm{SiO}_{2}$ (quartz) meningkatakan kekerasan komposit aluminium yang diperkuat serbuk silika. Deqing dan Ziyuan [8] meneliti mekanisme penguatan yang terjadi antara aluminium dengan serbuk silika pada pembuatan komposit dengan metode metalurgi serbuk. Hasil pengamatan yang dilakukan dengan SEM yang di-fit dengan EDS, menunjukkan terjadi reaksi terbentunya $\alpha \mathrm{Al}_{2} \mathrm{O}_{3}$ pada sekeliling serbuk $\mathrm{SiO}_{2}$. Hal ini mengakibatkan terjadi mekanisme penguatan pada komposit aluminium yang diperkuat $\mathrm{SiO}_{2}$. Penelitian yang dilakukan oleh Bhatt, dkk. [9] menyebutkan bahwa penambahan sebanyak $5 \%$ berat $\mathrm{SiO}_{2}$ ke dalam Al-Mg, meningkatkan kekerasan bahan komposit. $\mathrm{SiO}_{2}$ mengakibatkan terbentuknya fase $\mathrm{MgAl}_{2} \mathrm{O}_{4}$ yang bersifat keras. Proses sinter mempengaruhi sifat bahan komposit matrik logam dari proses metalurgi 
serbuk. Untuk mendapatkan parameter proses sinter, maka dalam penelitian diteliti pengaruh temperatur dan waktu sinter terhadap densitas dan porositas komposit aluminium yang diperkuat limbah geothermal.

\section{METODE PENELITIAN}

Bahan limbah geothermal yang digunakan adalah limbah geothermal dari Pembangkit Listrik Tenaga Panas Bumi (PLTPB) di Dieng. Bahan lumpur limbah, selanjutnya dikeringkan dan diayak (sieving) dengan screen ukuran mesh 400 sehingga didapat serbuk geothermal dengan ukuran $<32 \mu \mathrm{m}$. Untuk meningkakan kandungan silika pada limbah geothermal, dilakukan pengolahan limbah geothermal (pre-treatment process). Proses pre-treatment dilakukan adalah proses kalsinasi dan caustic digestion. Proses kalsinasi dilakukan dengan memanaskan limbah geothermal pada suhu $850^{\circ} \mathrm{C}$ selama $3 \mathrm{jam}$. Tujuan proses kalsinasi adalah untuk membakar unsur - unsur yang merugikan, seperti sulfur, kabon dll. Selain dengan proses kalsinasi, proses pre-treatment juga dilakukan dengan metode caustic digestion, metode ini menghasilkan silika gel dari limbah geothermal. Produk hasil pre-treatment selanjutnya dikarakterisasi dengan uji komposisi dengan AAS, indentifikasi fasa dengan XRD dan pengamatan morfologi dengan SEM/EDS.

Pembuatan komposit matrik aluminium dilakukan dengan proses powder metallurgy. Serbuk aluminium yang digunakan adalah aluminum fine powder dengan kemurnian $99 \%$. Variasi penambahan \% berat bahan penguat limbah geothermal $10 \%$. Campuran antara serbuk limbah geothermal dengan serbuk alumunium di-mixing di dalam turbula mixer yang ditambahkan bola-bola baja selama 8 jam. Pembuatan green body spesimen uji dilakukan dengan kompaksi penekanan tunggal dengan tekanan kompaksi $250 \mathrm{MPa}$. Proses sinter dilakukan dengan dapur elektrik pada lingkungan gas argon dengan variasi temperatur sinter : $500{ }^{\circ} \mathrm{C}, 550{ }^{\circ} \mathrm{C}$ dan $600{ }^{\circ} \mathrm{C}$ dengan waktu penahanan sinter 1,2 dan 4 jam.

Pengujian densitas dilakukan berdasarkan hukum Archimedes. Peralatan yang digunakan adalah timbangan merk Satorius dengan ketelitian 0.001 gram dan fluida air. Skema alat uji densitas ditunjukkan pada Gambar 1. Densitas bahan komposit dapat dicari dengan Persamaan (1).

$$
\rho=\frac{W_{\text {air }}}{\left(W_{\text {air }}-W_{\text {fluid }}\right)} x \rho_{\text {fluida }}
$$

dimana:

$$
\begin{aligned}
& w_{\text {air }}=\text { berat sampel di udara } . \\
& w_{\text {fluid }}=\text { berat sampel di dalam cairan } . \\
& \rho_{\text {fluid }}=\text { densitas cairan }
\end{aligned}
$$

Timbangan

Merk Satorius dengan ketelitian 0,001 gr

kawat

Fluida (air)

Spesimen komposit

Gambar 1. Skema alat uji densitas.

\section{HASIL DAN PEMBAHASAN}

Proses kalsinasi atau karbonasi bertujuan untuk menghilangkan komponen organik yang terdapat pada suatu material, sehingga akan meningkatkan kandungan senyawa anorganik terutama $\mathrm{SiO}_{2}$. Suhu kalsinasi yang digunakan untuk serbuk geothermal adalah $850^{\circ} \mathrm{C}$ selama 3 jam, pemilihan suhu tersebut karena suhu $850^{\circ} \mathrm{C}$ dianggap suhu optimum untuk menghilangkan senyawa organik yang terkandung didalam serbuk geothermal. Setelah serbuk geothermal dikalsinasi, dilanjutkan proses karakterisasi material menggunakan metode AAS dan XRD untuk mengetahui perubahan komposisi kimia dan fasa kristalin dari serbuk geothermal. Pengujian AAS dengan 
menggunakan alat Shimadzhu tipe AA-6650. Sedangkan pengujian XRD menggunakan difraktometer XRD-6000 merk Shimadzu dengan kondisi operasi melibatkan radiasi $\mathrm{Cu}$ pada $40.0 \mathrm{kV} 30 \mathrm{~mA}$ dan sampel discan dengan range sudut (20) $3^{\circ}-70^{\circ}$. Pengaruh proses pre-teatment terhadap \% berat $\mathrm{SiO}_{2}$ ditunjukkan pada Gambar 2.

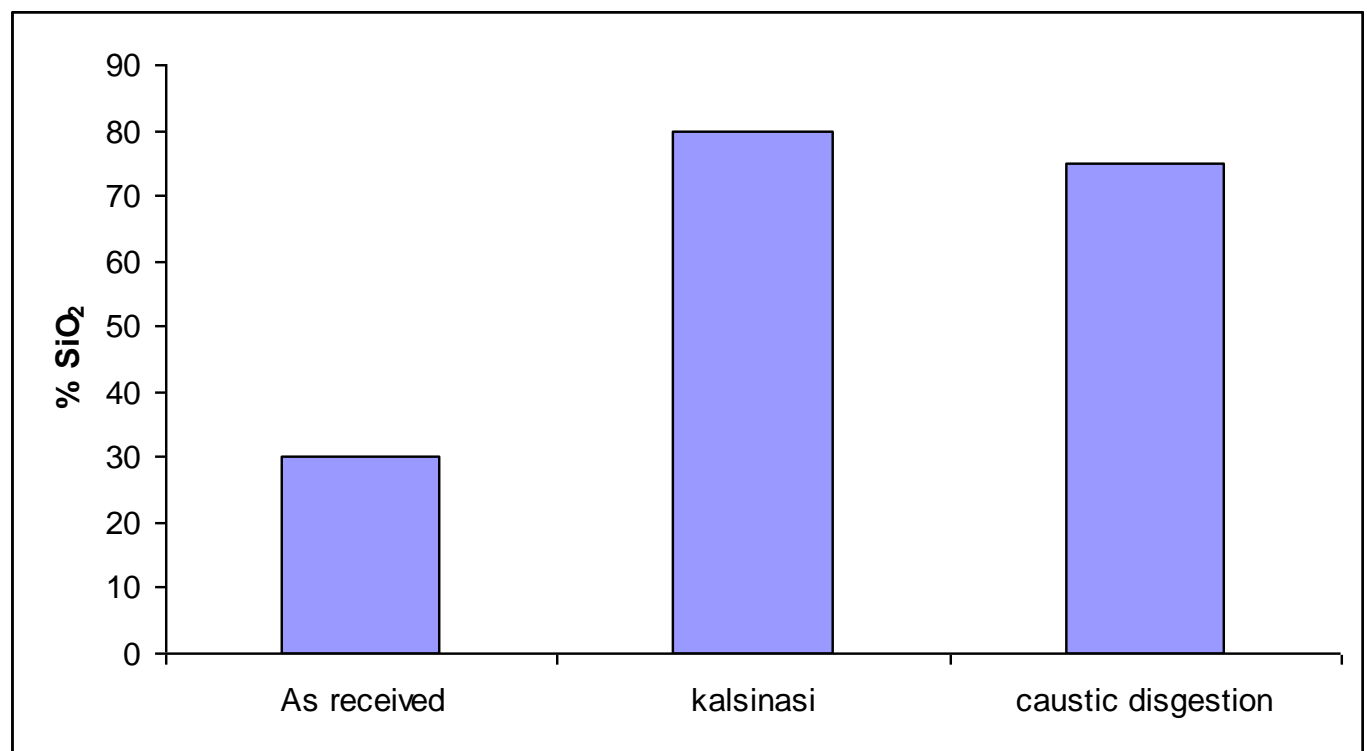

Gambar 2. Pengaruh proses pre-treatment terhadap $\% \mathrm{SiO}_{2}$ dalam limbah geothermal

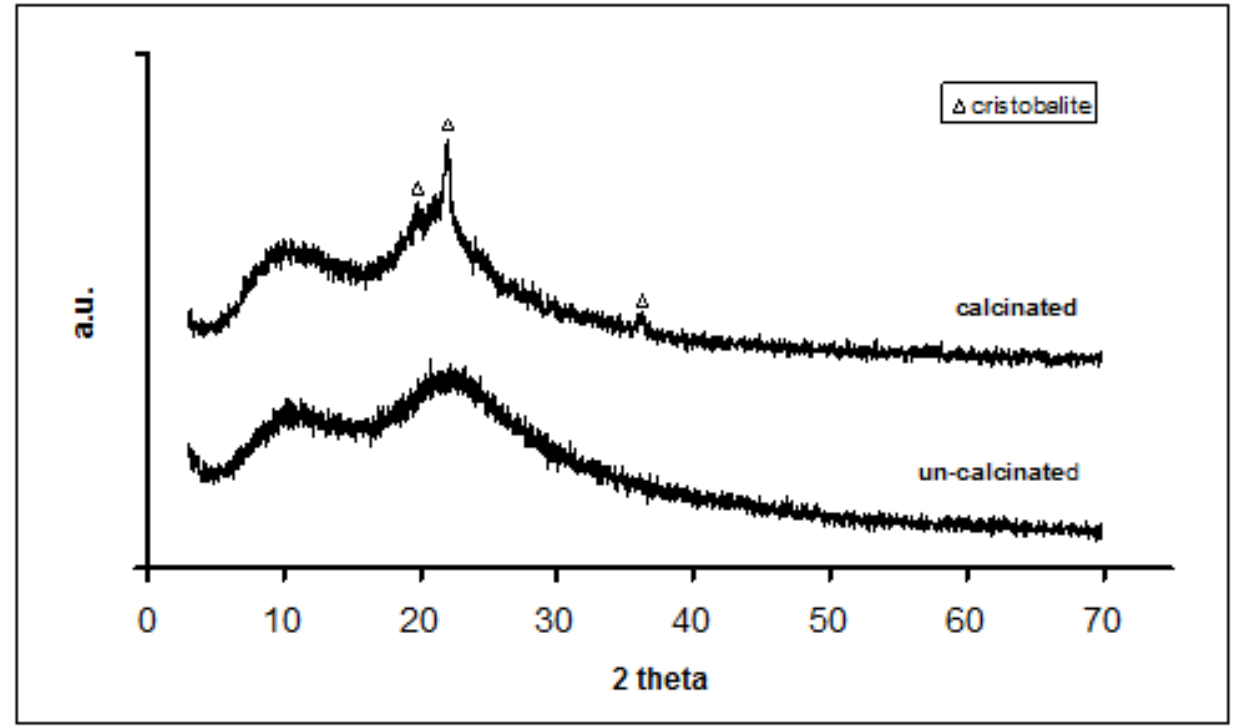

Gambar 3. Hasil pengujian XRD serbuk limbah geothermal sebelum dan sesudah kalsinasi

Dari Gambar 2 tersebut dapat diambil kesimpulan bahwa dengan proses kalsinasi $\% \mathrm{SiO}_{2}$ meningkat dari sekitar $30 \%$ menjadi $80 \%$. Proses caustic disgestion meningkatkan $\% \mathrm{SiO}_{2}$ dari $30 \%$ menjadi sekitar $75 \%$. Gambar 3 . menunjukkan hasil pengujian XRD serbuk limbah geothermal sebelum dan sesudah kalsinasi. Gambar 3 menunjukkan bahwa akibat proses kalsinasi terjadi perubahan dari $\mathrm{SiO}_{2}$ amorf menjadi $\mathrm{SiO}_{2}$ kristalin (cristobalite).

Densitas dan porositas komposit ditunjukkan pada Gambar 4. Grafik pada gambar 4 tersebut menunjukkan perilaku sinter yang berbeda untuk tiap suhu sinter yang berbeda. Sinter pada temperatur $500{ }^{\circ} \mathrm{C}$ menunjukkan bahwa dengan penahanan 1 jam, didapat densitas komposit tertinggi. Penambahan waktu sinter mengakibatkan menurunnya densitas komposit. Sinter pada temperatur $550{ }^{\circ} \mathrm{C}$ meningkatnya waktu sinter dari 1,2 ke 4 jam mengakibatkan meningkatnya densitas komposit. Perilaku berbeda ditunjukkan pada proses sinter pada suhu $600{ }^{\circ} \mathrm{C}$. Pada temperatur sinter $600{ }^{\circ} \mathrm{C}$, densitas tertinggi didapat pada waktu sinter 2 jam. Densitas pada sinter selama 2 jam meningkat jika dibandingkan sinter pada waktu 1 jam. Penambahan waktu sinter menjadi 4 jam, justru menurunkan densittas komposit. 


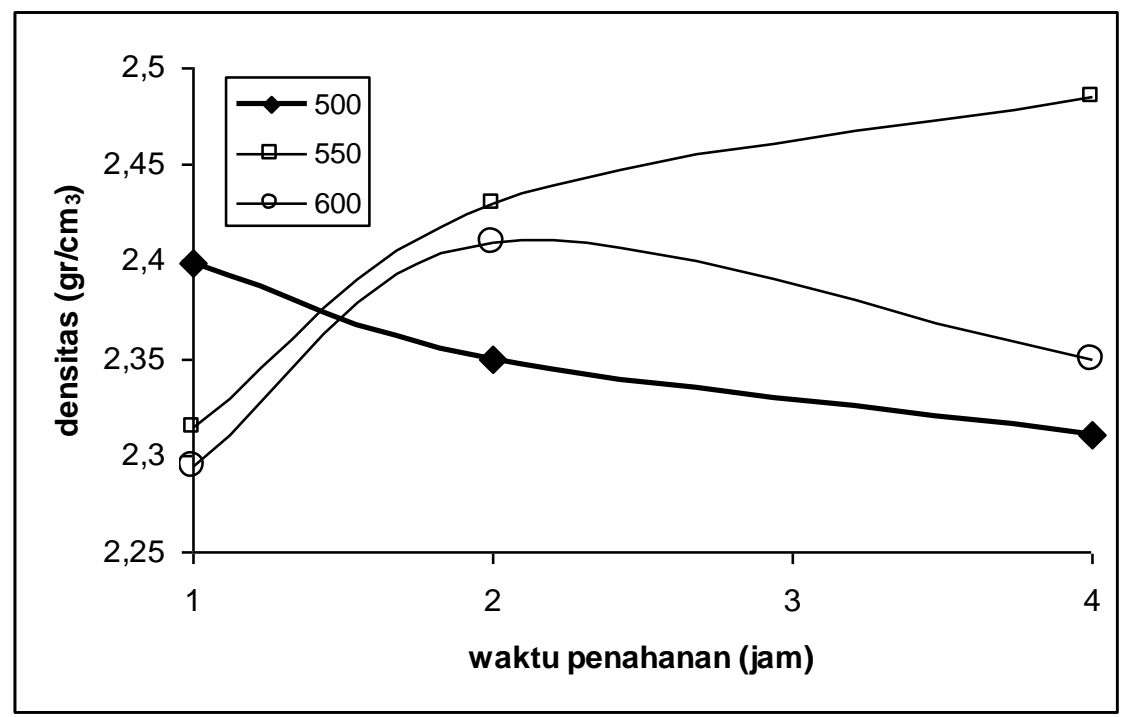

Gambar 4. Pengaruh waktu dan temperatur sinter terhadap densitas komposit.

Pengaruh temperatur dan waktu sinter terhadap porositas komposit, ditunjukkan pada Gambar 5. Grafik pada Gambar menunjukkan bahwa porositas terendah didapat pada temperatur $550^{\circ} \mathrm{C}$ dengan waktu 4 jam.

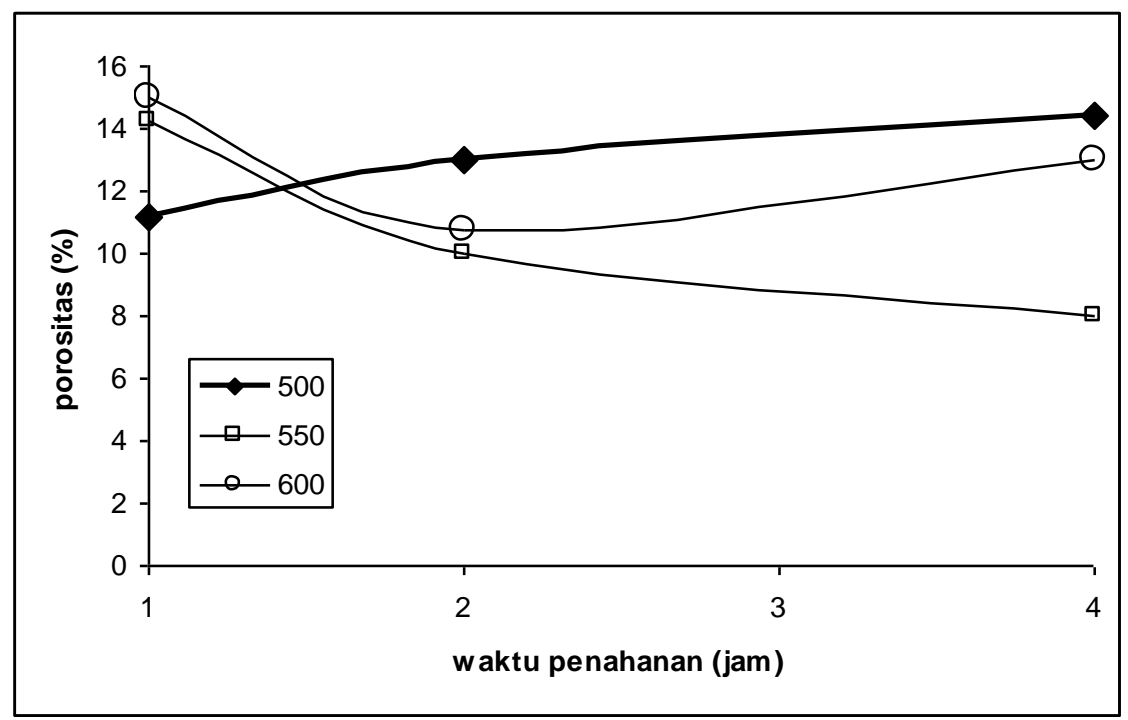

Gambar 5. Pengaruh waktu dan temperatur sinter terhadap porositas komposit

\section{KESIMPULAN}

Dari penelitian ini dapat disimpulkan sebagai berikut :

1) Proses kalsinasi meningkatkan $\% \mathrm{SiO}_{2}$ dari $30 \%$ menjadi $80 \%$, caustic disgestion meningkatkan $\% \mathrm{SiO}_{2}$ menjadi $75 \%$.

2) Porositas terendah sebesar $8 \%$ didapat pada temperatur sinter $550{ }^{\circ} \mathrm{C}$ dengan waktu penahanan 4 jam.

\section{DAFTAR PUSTAKA}

[1] Brophy,P., 1997, Enviromental Advantages to The Utilization of Geothermal Energy, Renewable Energy, Vol. 10, No. 213, pp. 361-311.

[2] Lund, J.W., 1995, Use of Silica Waste from The Cerro Prieto Geothermal Field as Construction Material, GHC Bulletin, http://geoheat.oit.edu/pdf/bulletin/bi073.pdf. Diakses 1 Februari 2012.

[3] Suprapto, S.J. 2009, Panas Bumi Sebagai Sumber Energi dan Penghasil Emas, Warta Geologi, Volume 4 (2).

[4] Premuzic, R., dan Lin, M.S., 2003, Conversion of Geothermal Waste to Commercial Product Including Silica, US Patent No : US. 6.537.796.BI. 
[5] Gallup, D.L., 2009, Production engineering in geothermal technology: A review, Geothermics 38 (2009), pp : 326-334.

[6] Zuhailawati,H., Samayamutthirian, P., dan Mohd Haizu, C.H., 2007, Fabrication of Low Cost of Aluminium Matrix Composite Reinforced With Silica Sand, Journal of Physical Science, Vol. 18(1), pp : 47-55.

[7] Hamouda, A.M.S., Sulaiman, S., Vijayaram, T.R., Sayuti, M., dan Ahmad,.H.M, 2007, Processing and characterisation of particulate reinforced aluminium silicon matrix composite, Journal of Achievements in Materials and Manufacturing Engineering, Vol : 25 (2), pp : 11 - 16.

[8] Deqing, W., dan Ziyuan, S., 2001, Aluminithermic Reduction of Silica for the Synthesis of Alumina-AluminiumSilicon Composite, Journal of Materials Synthesis and Processing, Vol : 9 (5), pp : 241 - 246.

[9] Bhatt, J., Balachander, N., Shekher, S., Karthikeyan, R., Peshwe, D.R., Murty, B.S., 2012, Synthesis of nanostructured $\mathrm{Al}-\mathrm{Mg}-\mathrm{SiO} 2$ metal matrix composites using high-energy ball milling and spark plasma sintering, Journal of Alloys and Compounds 536S, pp : s35 - s40. 